www.jmscr.igmpublication.org

Impact Factor 5.244

Index Copernicus Value: 5.88

ISSN (e)-2347-176x ISSN (p) 2455-0450

crossref DOI:_http://dx.doi.org/10.18535/jmscr/v4i3.02

\title{
Evaluation of Carotid Intima -Media Thickness in Patients with Chronic Obstructive Pulmonary Disease
}

Authors

\section{Dr Rajani .M., Dr Manoj.D.K, Dr Smithanair}

${ }^{1}$ Associate Professor, Dept of Pulmonary Medicine ,Pariyram Medical College, Kannur, Kerala, India.

${ }^{2}$ Professor, Department of Pulmonary Medicine, Pariyaram Medical College, Kannur, Kerala, India

${ }^{3}$ Junior Resident

${ }^{4}$ Department of Pulmonary Medicine, Pariyaram Medical College, Kannur, Kerala, India

Corresponding Author

Dr Rajani M.

Associate Professor, Department of Pulmonary Medicine, Pariyram Medical College, Kannur, Kerala, India Email id: sajeevanrajani@gmail.com, Mobile no: 9447263597

\footnotetext{
Abstract

Background: Chronic obstructive pulmonary disease [COPD] can be associated with major comorbid diseases including atherosclerosis of blood vessels.Carotid atherosclerosis as characterised by increased intima-media thickness [IMT] is an indicator of atherosclerosis burden and cardiovascular disease risk.

Aims: To evaluate the changes of carotid intima-media thickness in patients with chronic obstructive pulmonary disease. To determine the relation between severity of COPD and increased intima-media thickness.

Materials and Methods: A case control study was done among 40 patients with COPD and 40 healthy subjects(Aged 50-65yrs) using carotid B mode duplex ultrasonography with high frequency probe (7.5 $\mathrm{MHz}$.Levels more than or equal to $1.2 \mathrm{~mm}$ was defined as increased IMT.The severity of COPD was assessed by spirometry. An additional risk factor which was studied was plaques in carotid artery.

Results: Twenty six patients with COPD and ten from control group had increased Intima-media thickening, which was highly significant[p=0.000]. The relation between severity of COPD and increased IMT was clinically significant but statistically notsignificant[p=.069].

Thirty patients with chronic obstructive pulmonary disease and twelve from control group had increased incidence of soft plaques, which was also highly significant[p $=0.000]$.

Conclusion: Carotid intima media thickness measurement can be effectively used as an early predictor of cardiovascular risk assessment in patients with chronic obstructive pulmonary disease.

Key Words: COPD,Carotid Intima -Media Thickeness,Atherosclerosis
} 


\section{Introduction}

Chronic obstructive pulmonary disease (COPD) is usually progressive and linked to an abnormal inflammatory reaction of the lungs $\left.{ }^{(1},{ }^{2}\right)$. Even though principally a lung disease, COPD is documented to have significant systemic outcomes that may affect morbidity and mortality $^{(3)}$. Especially, it is related to a noticeably increased risk of cardiovascular disease ${ }^{(4)}$. The mechanisms responsible for the association between COPD and atherosclerosis are still unclear, but the most likely are chronic systemic inflammation, hypercoagulable status, platelet activation and oxidative stress ${ }^{(5)}$. Preclinical carotid atherosclerosis, characterized by increased intima-media thickness (IMT), is an indicator of atherosclerosis burden and cardiovascular disease risk $^{(6)}$. COPD was correlated with increased IMT. Additionally, increased IMT was connected to increased cardiovascular mortality in patients with $\operatorname{COPD}^{(7)}$. There is a growing body of literature that indicates that chronic obstructive pulmonary disease (COPD) is an independent risk factor for cardiovascular disease ${ }^{(8)}$.For every $10 \%$ decrease in lung function (as measured by forced expiratory volume in $1 \mathrm{~s}, \mathrm{FEV}_{1}$ ) cardiovascular mortality increases by nearly $30 \%{ }^{(9)}$.

Cardiovascular conditions that have been reported to occur with a greater frequency in patients with COPD than in the general population are atherosclerosis, coronary artery disease (CAD), congestive heart failure (CHF), peripheral vascular disease (PVD), and cardiac arrhythmias (10)

Low grade systemic inflammation plays the pivotal role in linking COPD with cardiovascular disease $^{(11)}$.

Reduced $\mathrm{FEV}_{1}$ itself is a risk factor for cardiovascular mortality in patients of COPD irrespective of conventional risk factors. Every $10 \%$ decrease in $\mathrm{FEV}_{1}$ increases all cause mortality by $14 \%$, cardiovascular mortality by $28 \%$, and nonfatal coronary event by almost $20 \%$, after adjustments for relevant confounders such age, sex, smoking status, and treatment assignment $^{(12) .}$ Atherosclerosis is the leading cause of coronary heart disease, stroke, and PVD $^{(13,14)}$. Carotid intima-media thickness (CIMT) is a marker of preclinical carotid atherosclerosis, and can be used to detect atherosclerosis burden as well as risk assessment of cardiovascular disease ${ }^{(15)}$

\section{Aims and Objectives}

1. To evaluate the changes of carotid intimamedia thickness in patients with chronic obstructive pulmonary disease.

2. To determine the relation between severity of COPD and increased intima-media thickness.

3. To evaluate the presence of plaques in carotid artery in COPD patients

\section{Materials and Methods}

Study design: A case control study.

Study population \& Study sample: 40 patients with COPD \& 40 healthy subjects as control. They were matched for age, sex \& smoking.

Study setting: OPD of Respiratory Medicine, ACME, Pariyaram.

Study period: 1-04-2015 to 30-09-2015 Cases and controls were selected who attended the OPD consecutively and those who met the selection criteria.

Inclusion Criteria: Those who consented for the study.

Exclusion Criteria: Persons with Hypertension, Diabetes mellitus, Dyslipidaemia, Cardiovascular diseases and other lung diseases. Smoking was not taken as an exclusion criteria in either study or control group.

Cases were those who diagnosed as COPD. The healthy bystanders were selected as controls.

COPD diagnosis made from history and clinical examination and confirmed by spirometry.

To obtain uniformity of distribution, all patients and controls were selected from nearly same age range (50yrs-65yrs), sex and smoking. 


\section{JMSCR Vol||04||Issue||03||Page 9591-9598||March}

FEV1 and FEV1/FVC measurements of both patient and control group were obtained by Spirometry.

The diagnosis of COPD and its severity were determined according to GOLD criteria.

\section{Caritid intima media thickeness measurement:}

Carotid IMT were bilaterally measured by carotid B-mode Duplex ultrasonography with high frequency probe $(7.5 \mathrm{MHz})$. Bilateral common carotid artery (CCA), carotid bulb, bifurcation of common carotid artery, proximal internal carotid artery(ICA) \& external carotid artery (ECA) were visualised. IMT measured from CCA at the point of maximal thickness. Increased IMT was defined as $\geq 1.2 \mathrm{~mm}$.Plaques were assessed based on echogenicity as well as shadow of the plaques. In case of high bifurcation of carotid, proximal ICA \& ECA cannot be visualised. Flow velocity \& pattern were also assessed.

\section{High-resolution Doppler Ultrasound:}

Advantages: Low cost compared to other modalities of imaging. Comfort for patient studied. No need of IV contrast. No exposure to radiation

Statistical analysis: Data were entered and analysed using the Statistical Package for the
Social Sciences (SPSS) version 12 software. $p$ value less than 0.05 was considered significant.

\section{Results}

In COPD cases 26 cases (65\%) showed increased intima media thickeness. In control group only 10(25\%) showed increased intima media thickeness. This is statistically highly significant $(\mathrm{p}=0.000)$.

In this study in case of COPD patients 30 patients $(75 \%)$ were having increased incidence of soft plaques. Where as in control group only12 (30\%) were having increased incidence of soft plaques. This is also found to be statistically highly significant $\mathrm{N}(\mathrm{p}=0.000)$.

There was 18 (46\%) mild COPD,6(15\%) moderate COPD, 10 (24\%) severe COPD and 6 $(15 \%)$ very severe COPD in our study. In severe and very severe cases about $77 \%$ had increased intima media thickeness whereas in mild \& moderate cases only $44 \%$ had intima media thickeness. The relation between severity of COPD and increased IMT was clinically significant but statistically not significant $[\mathrm{p}=.069]$.

\section{Presence of Plaque among cases and controls}

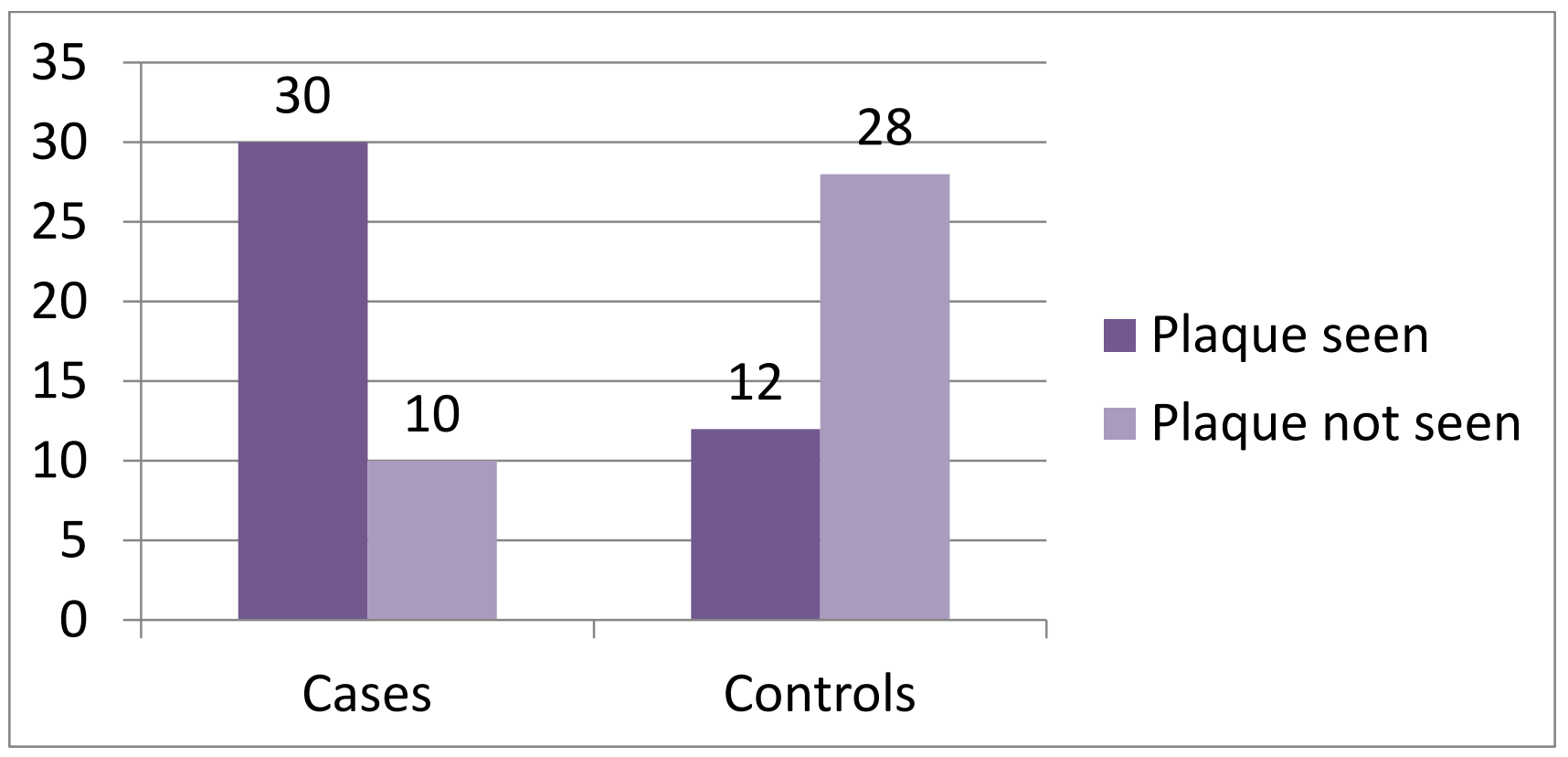




\section{Increased IMT among Cases and Controls}

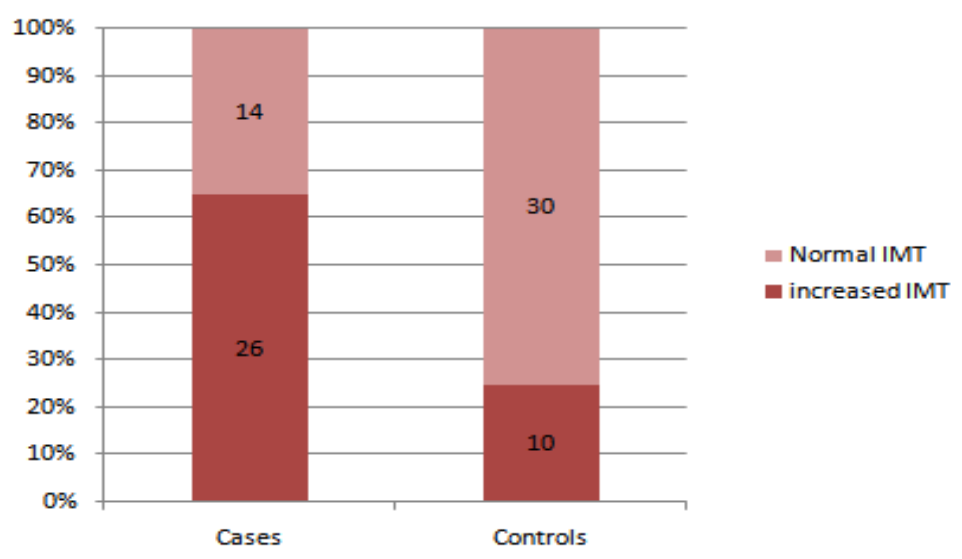

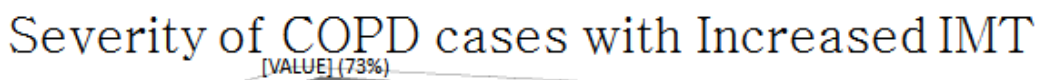

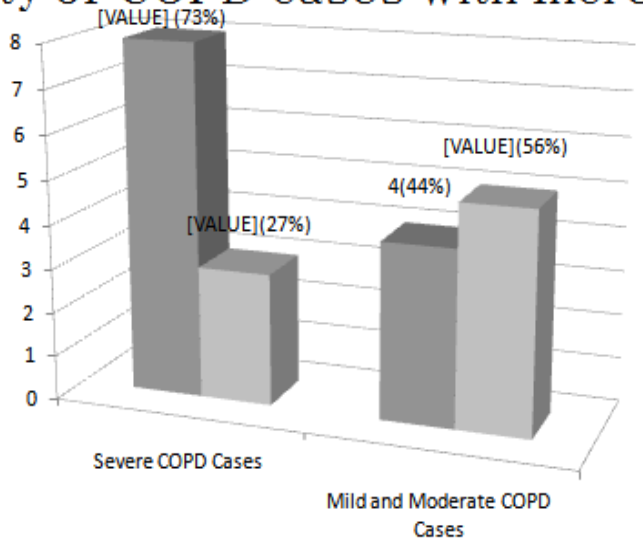

Increased IMT

\section{Increased IMT}

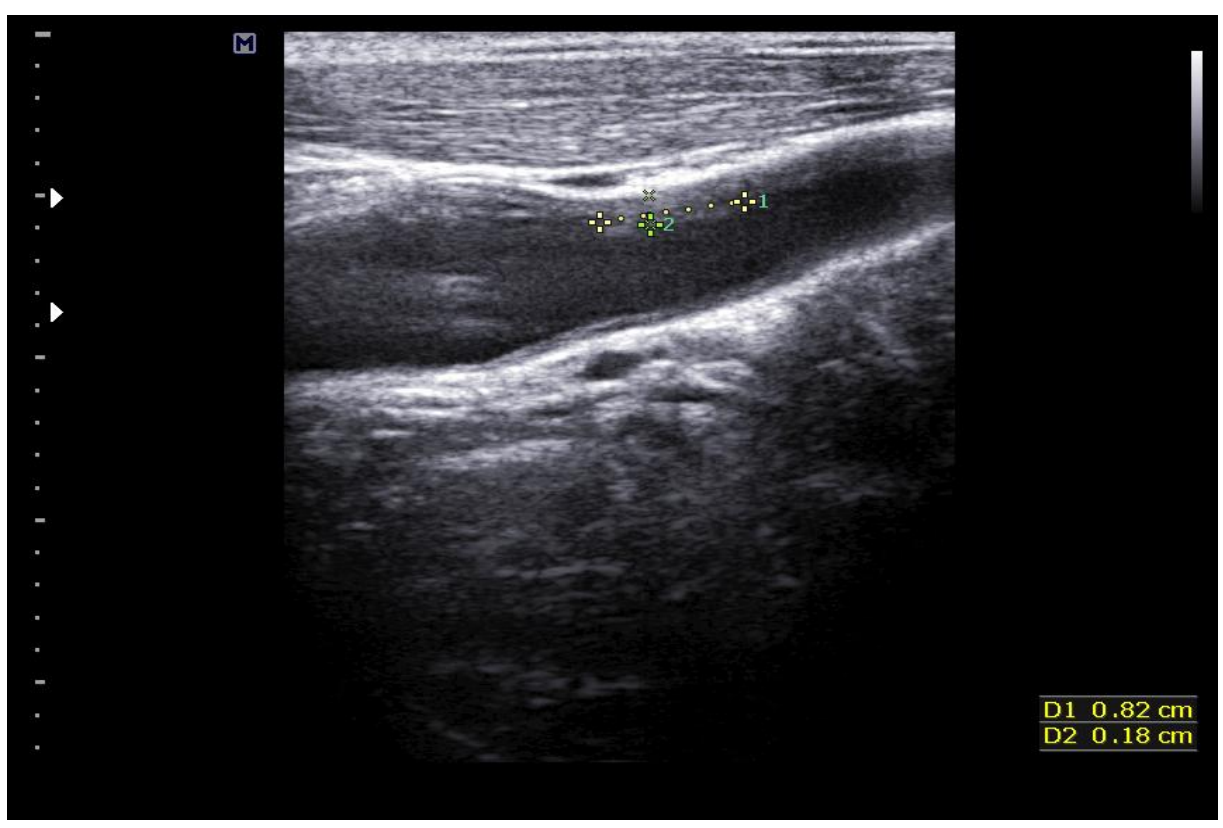




\section{JMSCR Vol||04||Issue||03||Page 9591-9598||March}

\section{SOFT PLAQUES}

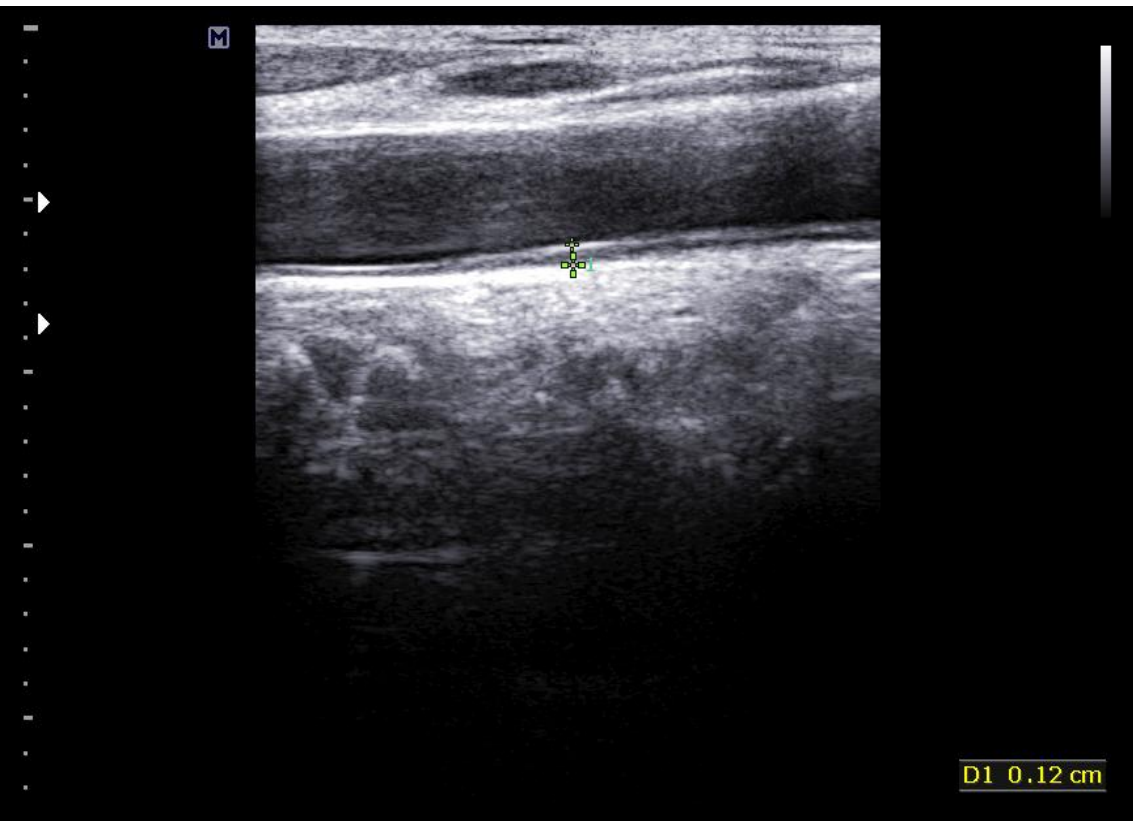

\section{FLOW VELOCITY AND PATTERN}

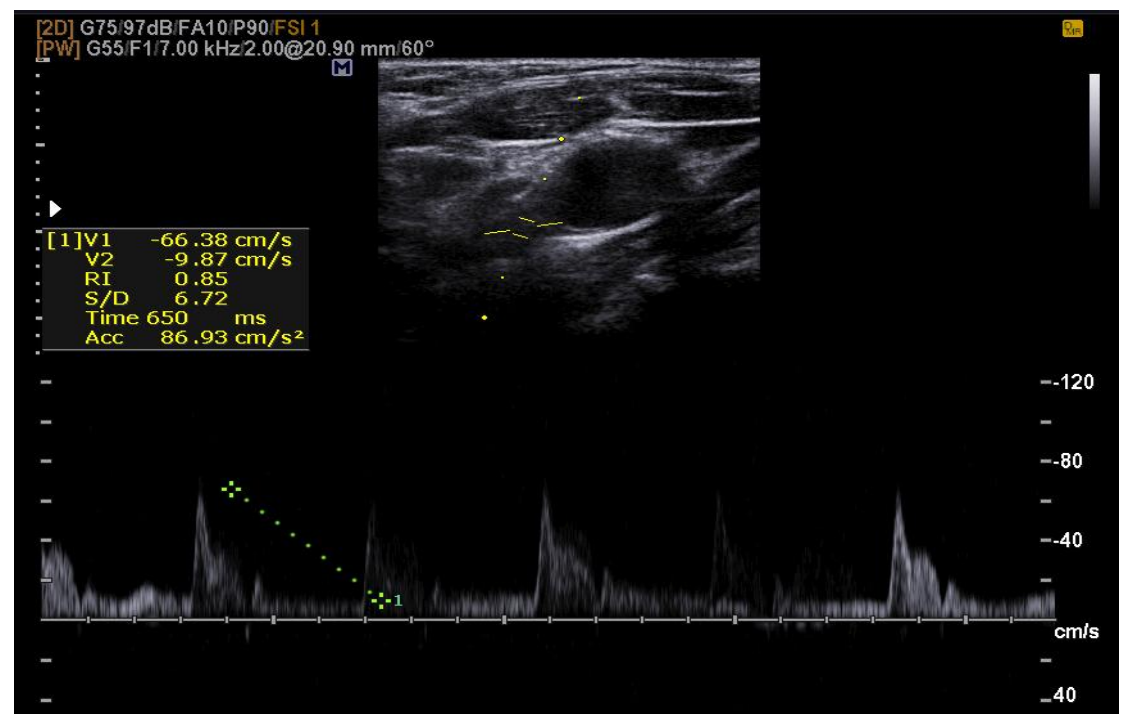

\section{Discussion}

The all atherothrombotic effect of COPD has more proven by the increased risk of ischemic stroke in patients with COPD $^{(16)}$. Pobeha et al. found the relationship between increased CIMT and increased cardiovascular disease risk with airway obstruction severity in COPD patients ${ }^{(17}$ In the study of Besir et al, CIMT in COPD patients was found to be higher than of healthy controls' one. The mean CIMT values had a significant negative correlation with FEV1 measurment $^{(18)}$

Van Gestel et al. demonstrated that regardless of smoking status, and other comorbidities, moderate to severe COPD was independently associated with increased CIMT. Increased CIMT of COPD patients had higher cardiovascular mortality risk, compared to COPD patients with normal CIMT $^{(19)}$.

Kim et al. established that COPD was associated with increased CIMT. Furthermore, the CIMT was significantly correlated with a decrease in lung function. In addition, increased CIMT was related with increased cardiovascular risk in patients with COPD. CIMT was significantly linked to FEV1, FVC, and FEV1/FVC ${ }^{(20)}$ Cardiovascular illness is the major reason of death in patients with mild to moderate 
$\left.\mathrm{COPD}^{(21}\right)$, and a decreased FEV1 has been documented to be an indicator for cardiovascular mortality $^{(22)}$. The other studies proposed that reduced FEV1 is associated with increased ischemic heart disease risk, stroke and sudden death $^{(23,24)}$. In another study, reduced FEV1 was correlated with endothelial dysfunction and atherosclerosis $^{(25) .}$

Our study showed statistically significant asassoiation of CIMT in COPD compared with healthy controls. We also studied the presence of plaques in both controls and cases. In COPD patients 30 patients $(75 \%)$ were having increased incidence of soft plaques. Where as in control group only12 (30\%) were having increased incidence of soft plaques. This is also found to be statistically highly significant $(\mathrm{p}=0.000)$. Our study also showed clinically significant association between severity of COPD and CIMT. In a study conducted by Omer karakas et al CIMT in COPD patients was found to be higher than healthy controls' one. Additionally, the increased CIMT was significantly correlated with a decrease in lung function ${ }^{26}$

It is now well recognized that cardiovascular disorders are the leading cause of morbidity and mortality in patients with moderate COPD. However, there is a paucity of validated biomarkers that can be used in clinical practice to accurately risk stratify such patients for early and aggressive interventions. Irrespective of smoking status and other co-morbidities, moderate to severe COPD was independently associated with increased IMT of the common carotid artery and COPD patients with increased IMT, independent of their lung function, had increased risk of total and cardiovascular mortality compared to COPD patients with normal IMT. ${ }^{27}$ The mechanism for the association of COPD with increased carotid wall IMT is not well known. It is generally recognized that systemic inflammation exists in COPD and is associated with increased cardiovascular morbidity and mortality. ${ }^{28}$ However, a previous study indicated that systemic inflammatory biomarkers such as C-reactive protein were not associated with the progression of carotid wall IMT, ${ }^{29}$ suggesting that other potential mechanisms are involved. Another possibility could be shared risk factors between COPD and carotid disease such as smoking. In our analysis, however, we adjusted for smoking status and still found a significant relationship between COPD and increased carotid wall IMT arguing against this theory. In addition, a recent study showed that mean carotid IMT in male smokers with airflow obstruction was greater than that of control smokers and never smokers, suggesting that airflow limitation rather than smoking per se is associated with atherosclerosis. ${ }^{30} \mathrm{IMT}$ measurements are non-invasive, reproducible, accessible (in most vascular laboratories) and can be performed quickly and relatively inexpensively, these data suggest that carotid IMT is a very promising biomarker to risk-stratify patients with COPD for mortality and in particular for cardiovascular mortality, which affects 30$50 \%$ of COPD patients. ${ }^{31,32}$

\section{Conclusion}

We suggest Carotid IMT measurements can be used in the determination of early atherosclerosis and cardiovascular risks in the patients with COPD. The frequency of carotid plaques is high in COPD patients which can identify high risk of having manifest and subclinical atherosclerosis. Severity of COPD is directly proportional to IMT and atherosclerosis.

Limitation: Small size of population studied. No biomarkers of inflammation assessed. Single centered study

Strength of Study: Comorbidities were diagnosed and excluded. Non invasive, reproducible, accessible \& relatively inexpensive

Funding: No funding sources

Conflict of interest: None declared

Ethical approval: The study was approved by the Institutional Ethics Committee 


\section{References}

1. Pauwels R, Buist A, Calverley P, Jenkins C, Hurd S.Global strategy for the diagnosis, management and prevention of chronic obstructive pulmonary disease. NHLBI/WHO global initiative for chronic obstructivelung disease (GOLD) workshop summary. Am J RespirCrit Care Med 2001; 163: 1256-76.

2. Global Initiative for Chronic Obstructive Lung Disease. Global Strategy for the Diagnosis, Management and Prevention of Chronic ObstructivePulmonary Disease. NHLBI/WHO workshop report. Bethesda, National Heart, Lung and Blood Institute,April 2001; Update of the Management SectionsGOLD website 2003

3. Agusti AG. Systemic effects of chronic obstructive pulmonarydisease. Proc Am Thorac Soc 2005; 2(4): 367-70.

4. Sin DD, Man SFP. Chronic obstructive pulmonary disease as a risk factor for cardiovascular morbidity and mortality. Proc Am Thorac Soc 2005; 2(1): 8-11.

5. Fimognari FL, Scarlata S, Conte ME, Incalzi RA.Mechanisms of atherothrombosis in chronic obstructive pulmonary disease. International Journal of COPD 2008; 3(1): 89-96.

6. Baldassarre D, Amato M, Bondioli A, et al. Carotid artery intima-media thickness measured by ultrasonography i n normal clinical practice correlates well with atherosclerosis risk factors. Stroke 2000; 31(10) 2426-30

7. Kim SJ, Yoon DW, Lee EJ, Hur GY, Jung $\mathrm{KH}$, Lee SY,et al. Carotid atherosclerosis in patients with untreatedchronic obstructive pulmonary disease. Int $\mathbf{J}$ Tuberc Lung Dis 2011; 15

8. D.D. Sin, L. Wu, S.F. ManThe relationship between reduced lung function and cardiovascular mortality: a population-based study and a systematic review of the literatureChest, 127 (2005 Jun), pp. 1952-1959

9. D.D. Sin, S.F. ManChronic obstructive pulmonary disease as a risk factor for cardiovascular morbidity and mortality Proc Am Thorac Soc, 2 (2005), pp. 8-11

10. Aryal S, Diaz-Guzman E, Mannino DM. Epidemiology of comorbidities in chronic obstructive pulmonary disease: Clusters, phenotypes and outcomes. Italian Journal of Medicine 2012;6:276-84.

11. Fabbri LM, Luppi F, Beghé B, Rabe KF. Complex chronic comorbidities of COPD. Eur Respir J 2008;31:204-12

12. Hole DJ, Watt GC, Davey-Smith G, Hart CL, Gillis CR, Hawthorne VM. Impaired lung function and mortality risk in men and women: Findings from the renfrew and paisley prospective population study. BMJ 1996;313:711-6.

13. Ross R. The pathogenesis of atherosclerosis: A perspective for the 1990s. Nature 1993;362:801-9.

14. Faxon DP, Fuster V, Libby P, Beckman JA, Hiatt WR, Thompson RW, et al.; American Heart Association. Atherosclerotic vascular disease conference: Writing Group III: Pathophysiology. Circulation 2004;109: 2617-25

15. Schroeder EB, Welch VL, Evans GW, Heiss G. Impaired lung function and subclinical atherosclerosis. The ARIC study. Atherosclerosis 2005;180:367-73

16. Truelsen T, Prescott E, Lange P, Boysen G. Lung functionand risk of fatal and nonfatal stroke. TheCopenhagen City Heart Study. Int J Epidemiol 2001;30(1): 14551.

17. Pobeha P, Skyba P, Joppa P, Kluchova Z, Szaboova E,Tkac I, et al. Carotid intimamedia thickness in patients with chronic obstructive pulmonary disease. Bratisl Lek Listy 2011; 112(1): 24-8. 
18. Besir FH, Aydin LY, Yazgan O, Dumlu T, Erkan ME,Onder E, et al. Evaluation of carotis intima media thickness in chronic obstructive pulmonary disease patients. Tuberk Toraks 2012; 60(3): 238-245.

19. van Gestel YR, Flu WJ, van Kuijk JP, Hoeks SE, BaxJJ, Sin DD, et al. Association of COPD with carotid wall intima-media thickness in vascular surgery patients. Respiratory Medicine 2010; 104(5): 712-16.

20. Kim SJ, Yoon DW, Lee EJ, Hur GY, Jung $\mathrm{KH}$, Lee SY,et al. Carotid atherosclerosis in patients with untreated chronic obstructive pulmonary disease. Int $\mathrm{J}$ TubercLung Dis 2011; 15(9): 1265-70.

21. Sin DD, Anthonisen NR, Soriano JB, Agusti AG.Mortality in COPD: role of comorbidities. Eur Respir J2006; 28(6): 1245-57.

22. Sin DD, Wu L, Man SF. The relationship between reduced lung function and cardiovascular mortality: a populationbased study and a systematic review of the literature. Chest 2005; 127(6): 1952-59.

23. Jousilahti P,Vartiainen E, Tuomilehto J, et al. Symptoms of chronic bronchitis and the risk of coronary disease.Lancet 1996; 348(9027): 567-72.

24. Camilli AE, Robbins DR, Lebowitz MD. Death certificate reporting of confirmed airways obstructive disease.Am J Epidemiol 1991; 133(8): 795-800.

25. Zureik M, Benetos A, Neukirch C, Courbon D, Bean K, Thomas F, et al. Reduced pulmonary function is associated with central arterial stiffness in men. Am J Respir Crit Care Med 2001; 164(12): 2181-5.

26. Omer Karakas1, Nesat Cullu2, Ekrem Karakas1, Zafer Hasan Ali Sak3, Murat Yildizhan1, Erdem Daglioglu1, OsmanKonukoglu1, Ferit Dogan1 Evaluation of Carotid Intima-Media
Thickness In The Patients With Chronicobstructive PULMONARY Diseaseacta Medica Mediterranea.

27. Yvette R.B.M. van Gestel ${ }^{\mathrm{a}}$, Willem-Jan $\mathrm{Flu}^{\mathrm{b}}$, Jan-Peter van Kuijk ${ }^{\mathrm{b}}$, Sanne E. Hoeks ${ }^{\mathrm{a}}$,Jeroen J. ax ${ }^{\mathrm{c}}$, Don D. Sin $^{\mathrm{d}}$,Don Poldermans Association of COPD with carotid wall intima-mediathickne in vascular surgery patientsRespiratory MedicineVolume 104, Issue 5, May 2010, Pages 712- 71.

28. D.D. Sin, S.F. Man Why are patients with chronic obstructive pulmonary disease at increased risk of cardiovascular diseases? The potential role of systemic inflammation in chronic obstructive pulmonary disease

29. M.W. Lorenz, P. Karbstein, H.S. Markus, M. SitzerHigh-sensitivity C-reactive protein is not associated with carotid intima-media progression: the carotid atherosclerosis progression study Stroke, 38 (2007 Jun), pp. 1774-177

30. Iwamoto, A. Yokoyama, Y. Kitahara, N. Ishikawa, Y. Haruta, K. Yamane, et al.Airflow limitation in smokers is associated with subclinical atherosclerosisAm J Respir Crit Care Med, 179 (2009 Jan 1), pp. 35-40

31. N.R. Anthonisen, J.E. Connett, J.P. Kiley, M.D. Altose, W.C. Bailey, A.S. Buist, et al. Effects of smoking intervention and the use of an inhaled anticholinergic bronchodilator on the rate of decline of FEV1. The Lung Health Study JAMA, 272 (1994 Nov 16), pp. 1497-1505

32. L.P. McGarvey, M. John, J.A. Anderson, M. Zvarich, R.A. Wise Ascertainment of cause-specific mortality in COPD: operations of the TORCH Clinical Endpoint Committee Thorax, 62 (2007 May), pp. 411-415 